\title{
A REVIEW OF CLINICAL FEATURES AND X-RAY IMAGES IN PATIENTS WITH ANKYLOSING SPONDYLITIS WHO UNDERWENT TOTAL HIP ARTHROPLASTY
}

\author{
Nguyen Quoc Dung*, Nguyen Anh Tuan*
}

\section{ABSTRACT.}

Objective: To describe some clinical features and $\mathrm{X}$ - ray images of patients with ankylosing spondylitis who underwent total hip arthroplasty. Subject and method: This is a descriptive and cross-sectional study. 10 male patients with ankylosing spondylitis including 13 hips were underwent total hip arthroplasty using cementless cup at The Joint Surgery Department of 108 Military Central Hospital from May 2015 to May 2019. The mean follow-up period was 33 months (range from 6 to 56 months). Result and conclusion: The combined form accounts for $9 / 10$ patients. $10 / 10$ patients in the research group were operated at the onset of the disease. Limitation and loss of movement of the cervical spine occurred to $7 / 10$ patients, $8 / 10$ patients with thoracic spine and $9 / 10$ patients with lumbar spine. All 10 patients had injured hip in both sides. 9/13 hips suffered intense and consecutive pain. 11/13 patients suffered from loss of hip movement before surgery). 10/10 patients had signs of loss of spinal curvature, railway spine found in 4/10 patients, images of bone bridges and bamboo spine were presented in $5 / 10$ patients. Damages to pelvic joint mainly occurred during stage III - IV with 12/13 joints, $1 / 13$ joint during stage II. Injury to stage III and IV hips, according to BASRI - $\mathrm{h}$ accounted for 11/13 hip joints, $2 / 13$ in stage II. The quality of the femur classified by Dorr type A accounted for 7/13 femur, type $\mathrm{B}$ accounted for $3 / 13$ femur, type $\mathrm{C}$ accounted for $3 / 13$ femur.

*108 Military Central Hospital

Responsible person: Nguyen Quoc Dung

Email: dungnq@gmail.com

Date of receipt: 01/7/2021

Date of scientific judgment: 29/7/2021

Reviewed date: 19/8/2021
Keywords: Ankylosing spondylitis, total hip arthroplasty.

\section{INTRODUCTION}

Ankylosing spondylitis (AS) is a chronic rheumatology inflammatory disease. The pathogenesis mechanics is still unknown. It is clear that the disease is related to HLA - B27 antigen factor. $0.1-1 \%$ of the world population has the disease [1]. In Vietnam, 0.28 of the Northern population over 16year-old has this disease, mostly young men (90\% male under 30-year-old) with family history [2]

Ankylosing spondylitis patients have high chance of suffering from hip injury (26\% during onset, $96 \%$ during final phase [2]). Hip injuries occurred during final phase often left sequela such as severe pain, limited or loss of movement function. Patients who suffered from such sequela became the burden for the family and the society.

Hip arthroplasty will recover the hip function, improve the quality of life for patients who suffered from AS [2]. To review the results and enhance the quality of treatment, our objective is to provide descriptive analysis of clinical features and $X$-ray images of AS patients who underwent total hip arthroplasty.

\section{SUBJECT AND METHODOLOGY}

\subsection{Subject}

10 male patients who suffered from AS. 13 hips underwent total hip arthroplasty using cement-less cup from May 2014 to 
May 2019 at The Joint Surgery Department of 108 Military Central Hospital.

\subsection{Methodology}

Descriptive and cross-sectional study, no comparable group.

\subsection{Research criteria}

Clinical features

Age at the time of operation, time of onset, gender.

Types: Axial, peripheral, mixed.

Peripheral joints injuries: knee joint, shoulder joint, ankle joint.

Phases: onset, prodromal.

Spinal deformities: assess the ability to move, posture, shape of cervical spine, thoracic spine and lumbar spine. Measure the flexibility of lumbar spine using Schober score: Good: $4-6 \mathrm{~cm}$, Moderate: $1-3 \mathrm{~cm}$, Poor: $<1 \mathrm{~cm}$.

Hip: assess the pain intensity using VAS score: 4 levels: no pain: 0 point, mild pain: 1 - 3 point, moderate pain: 4 - 6 point, severe point: 7 - 10 point. Assess hip ROM: hip measurements according to the movements and hip ROM.

\section{$X$-ray images assessment}

Lumbar spine: assess the condition of cervical spine, thoracic spine and lumbar spine (loss of spinal curvature, bone bridges, railway spine and bamboo spine).

Sacroiliac: assess stages of injuries using Forestier classification. Grade I: loss of mineral in sacroiliac joint line; Grade II: images of abrasion, Grade III: Melorheostosis in joint line, partial arthrodesis; Grade: total arthrodesis.

Hip, femur: assess the severity of hip injury using BASRI - $\mathrm{h}$ (Bath Ankylosing Spondylitis Radiology Index - hip) [7]. Phase 0: normal, I: partial narrow joint line; II: narrow joint line, more than $2 \mathrm{~mm}$ on the other side; III: narrow joint line, less than $2 \mathrm{~mm}$ on the other side or signs of osteophyte; IV: signs of bone deformity or osteophyte > $1 \mathrm{~cm}$. Dorr classification for femur (table 1).

Table 1. Dorr classification

\begin{tabular}{|l|c|c|c|}
\hline \multicolumn{1}{|c|}{ Grade } & A & B & C \\
\hline Index & $0,58 \pm 0,01$ & $0,50 \pm 0,00$ & $0,42 \pm 0,01$ \\
\hline CI (medial - lateral) & $0,48 \pm 0,01$ & $0,39 \pm 0,01$ & $0,30 \pm 0,02$ \\
\hline CC & $0,57 \pm 0,02$ & $0,59 \pm 0,02$ & $0,64 \pm 0,02$ \\
\hline
\end{tabular}

\subsection{Data handling and analysis}

Data was analyzed using SPSS 16.0 software.

\section{RESULTS}

\subsection{Clinical features}

\section{Age, gender}

Age at the time of operation ranged from 21 to 58 years old (mean $35.6 \pm 13.7$ years old). Mean age at the time to diagnosed with AS is $27.7 \pm 8.4$ years old (from 16 to 45 years old).

10/10 patients are male.

Types, phases and peripheral injuries
9/10 mixed spondyloarthritis, 1/10 peripheral spondyloarthritis.

10/10 patients suffered from both hip injuries.

$10 / 10$ patients were at the prodromal phase.

Peripheral injuries: 5 femur, 2 shoulder, 1 ankle.

\section{Spinal deformities}

Cervical spine ROM: normal: 3 patients; limited: 5 patients; unmovable: 2 patients.

Thoracic spine ROM: movable: 2 patients; frozen, straight: 7 patients; frozen, hunchback: 1 patient. 
Table 2. Thoracic spine ROM (Schober score) $(\mathrm{n}=10)$

\begin{tabular}{|l|c|c|}
\hline \multicolumn{1}{|c|}{ Schober score (cm) } & Number & Range of motion \\
\hline$<1$ & 6 & Unmovable \\
\hline$\leq 1-3$ & 3 & Limited \\
\hline$\geq 4$ & 1 & Good \\
\hline Total & 10 & \\
\hline
\end{tabular}

$6 / 10$ patients have $<1 \mathrm{~cm}$ ROM which fall into the group that suffer from the loss of thoracic spine motor function.

Hip symptoms

Table 3. Pain intensity classification pre-op $(\mathrm{n}=13)$

\begin{tabular}{|l|c|}
\hline \multicolumn{1}{|c|}{ Pain intensity } & Number \\
\hline No pain & 2 \\
\hline Mild pain & 2 \\
\hline Moderate pain & 7 \\
\hline Severe pain & 2 \\
\hline Total & $\mathbf{1 3}$ \\
\hline
\end{tabular}

11/13 hip pain at different level, 9/13 mild and moderate pain.

Table 4. Hip motor function pre-op $(\mathrm{n}=13)$

\begin{tabular}{|l|c|c|c|c|}
\hline \multirow{2}{*}{ ROM } & \multirow{2}{*}{ Movable } & \multicolumn{2}{|c|}{ Unmovable } & \multirow{2}{*}{ Total } \\
\cline { 3 - 4 } & 2 & 4 & 7 & 13 \\
\hline Total & 2 & $40 i n t$ adhesion & \\
\hline
\end{tabular}

$11 / 13$ unmovable hips pre-op.

3.2. X-ray image assessment

Table 5. Spinal X-ray images $(\mathrm{n}=10)$

\begin{tabular}{|l|c|}
\hline \multicolumn{1}{|c|}{ Spinal X-ray images } & Number \\
\hline Loss of curvature & 10 \\
\hline Railway spine & 4 \\
\hline Bone bridge and bamboo spine & 5 \\
\hline
\end{tabular}

All spines lost curvature.

Table 6. Sacroiliac X-ray image (Forestier classification) $(n=13)$

\begin{tabular}{|l|c|}
\hline \multicolumn{1}{|c|}{ Grade } & Number \\
\hline II & 1 \\
\hline III & 4 \\
\hline IV & 8 \\
\hline Total & $\mathbf{1 3}$ \\
\hline
\end{tabular}

12/13 grade III and IV Forestier sacroiliacs.

Table 7. Hip X-ray image (BASRI - h) $(\mathrm{n}=13)$

\begin{tabular}{|l|c|}
\hline \multicolumn{1}{|c|}{ Stage } & Number \\
\hline II & 2 \\
\hline III & 5 \\
\hline IV & 6 \\
\hline Total & $\mathbf{1 3}$ \\
\hline
\end{tabular}

11/13 stage III and IV BASRI - $\mathrm{h}$ hip. 
Table 8. Dorr femur classification $(\mathrm{n}=13)$

\begin{tabular}{|l|c|}
\hline \multicolumn{1}{|c|}{ Classification } & Number \\
\hline $\mathrm{A}$ & 7 \\
\hline $\mathrm{B}$ & 3 \\
\hline $\mathrm{C}$ & 3 \\
\hline Total & $\mathbf{1 3}$ \\
\hline
\end{tabular}

Femur class A Dorr were the most common.

\section{DISCUSSION}

\subsection{Clinical features}

\section{Age, time to diagnose}

In our study, the mean age at the time of operation was $35,6 \pm 13,7$ years old, with the youngest at 21 and the oldest at 58 years old. Similar results were drawn from other authors: Mark R. Brinker (1996): 12 patients, mean age 35,4 $\pm 11,19$ (22 - 53 years old) [3]; Hatim Abid (2014): mean age 31 (20 55 years old) [4]; Jiss Joseph Panakkal (2015): 24 patients, mean age 36 [5].

In our study, the mean time to diagnose with AS is at $27.7 \pm 8.4$ years old; soonest at 16 years old, latest at 45 years old. According to Mark R. Brinker's study (1996), this time was determined at about 23 \pm 7.7 years old (ranged $12-40$ years of age) [3]. It takes an average of $7.4 \pm 3.3$ years from the time to diagnose to the hip arthroplasty for AS treatment to take place.

All patients in the sample group were in working age. They require help from others to perform daily tasks, which create economical and mental burden for parties involved. Hip arthroplasty helps patients maintain the motor function of the hip, reduce the liability and consequently improve the quality of life.

\section{Gender}

In our sample, all patients are male, which accords with the characteristics of AS (common in young male [1], [2]).
In several Vietnamese studies, the male/female patient ratio fluctuates from $5 / 1$ to $9 / 1$. Women patients tend to suffer from milder symptoms compared to men, which may lead to misdiagnosis [1]. Other studies suggested that $0.28 \%$ of Northern population, mostly young men (90\% 30s male) were diagnosed with hereditary AS [2].

Studies from international authors also suggested similar results. According to Rajesh Malhotra (2014), the male/female ratio is 3/1 [6]; Wanchun Wang (2014): 5.5/1 [7]; Jinzhu Zhao (2014): 6/1 [8].

\section{Types and peripheral injuries}

All patients hip injuries, hence the absence of spinal spondyloarthritis. The mixed type accounts for the majority of the sample (9/10, 1 peripheral type). The mixed type is the most common type of AS in Vietnam.

In our study, besides hip injuries, other peripheral injuries include femur, shoulder and ankle joint.

During follow-up, 1 patient underwent bilateral knee arthroplasty, which proved the development of the disease on the overall motion system, directly affect the quality of life, consequently create economical and mental burden for the patients and their families.

\section{Phases}

All patients in our sample underwent hip arthroplasty at the prodromal phase. The 
common characteristics among patients was severe hip pain, limited hip motor function or frozen joint.

All patients underwent internal medical treatment and saw no improvement. Two patients had been diagnosed with joint tuberculosis and underwent treatment. However, improvements were minor and patients could only be diagnosed with AS after clinical features were presented. Therefore, it can be concluded that misdiagnosis hindered the quality of treatment, consequently leading to higher chance of disabilities.

\section{Spinal deformities}

In our study, 7/10 patients suffered from limited and loss of cervical motor function. The number of patients in the sample suffered from similar symptoms in thoracic and lumbar spine is $8 / 10$ and $9 / 10$, respectively. It is explained that spinal deformities are the consequent of unnatural posture to reduce pain caused by inflammation. Bad posture at the initial stage is loss of lumbar lordosis, leading to kyphosis with increased cervical lordosis and loss of neck lateral flexion.

Arthrodesis in cervical spine limits the motor function (flexion, extension, lateral flexion and rotation). During check-up, cervical lordosis lead to excess chin-chest distance. In later stages, when the cervical spine was bent, patients suffer from loss of neck lateral flexion.

Arthrodesis in thoracic spine affect ligaments around the spine more than in sternocostal joint. It also decreases the thorac expansion, which lead to respiratory failure. Operations for patients with thoracic arthrodesis were often challenged during anesthetic due to effects to breathing capacity caused by spinal deformities. Therefore, those patients had to be ran through respiratory assessment pre-op. Besides, the positioning of anesthetic and during operation is also a challenging task.

In our study, 6/10 patients lost the lumbar spine motor function (Schober score $<1 \mathrm{~cm}$ ), while others had different levels of motor function (3 with limited ROM, Schober score: 1 - $3 \mathrm{~cm}$; 1 with normal ROM, Schober score: $\geq 4 \mathrm{~cm}$ ).

Lumbar spine injuries directly affect the anesthetic method during operation. Cases suffered from complete loss of lumbar spine motor function were anesthetized before operation. Among the 4 cases with lumbar spine motor function still presence, spinal anesthetic could not be performed on 2 patients due to failure of injection, therefore surgeons must perform traditional anesthetic. According to Hatim Abid (2014), 100\% of total hip arthroplasty cases on AS patients must be anesthetize despite trismus.

\section{Hip characteristics and indications to} total hip arthroplasty

All patients in our sample suffered from bilateral hip injuries. This result matched with Wanchun Wang's study (2014) [7]. This is also a popular characteristic among AS patient in later phases.

In the context of our study, 11/13 hips suffered from varied intensity of pain, 9/13 suffered from moderate to severe pain, which was an indication to hip arthroplasty. Normally, this symptom would disappear 1 week after operation. Hip pain in patients suffered from hip inflammation will present at hip and buttock area, possibly affect knee and femur. The pain was often described as 
dull, making it hard to determine the specific spot. The movement of patient may reduce pain intensity momentarily. The pain cause disturbance throughout the day, making the indication to hip arthroplasty a necessity.

The loss of hip motor function was common among our sample (11/13 hips, 7/13 at flexion arthrodesis) due to hip pain reduction position. According to Wanchun Wang (2004), 100\% of hips lost motor function pre-op [7]. Soft tissue contractor around joints and hip deformities caused limited motor function, preventing patients from normal movement, causing them to be bedridden. For a long period of time, patients would suffer from soft tissue contracture, amyotrophia, severe arthrodesis, soft tissue ulcer, osteoporosis, increase exposure to infection. The motor function enhancement post op is predictable.

In our sample, 3 patients underwent bilateral hip arthroplasty, 1 underwent one stage surgical, 2 underwent two stage surgical. 7 injured hips had not been operated due to various reasons: health condition and economical reasons. AS patients found out about the disease when they were young. The disease directly affects the musculoskeletal system, prevent patients from working. During prodromal phase, patients require care from others, becoming an economical burden for their family. It can be concluded that hip arthroplasty is still a problem for patients with hip injuries and AS.

\subsection{X-ray image}

Standard X-ray scanning provides great diagnosis value at a low cost. It is a crucial standard to diagnose the disease.

Spinal X-ray images shown unique symptoms for accurate diagnosis at late phases, when clinical symptoms were visible. 10/10 patients lost spinal curvature, 4/10 railway spine, $5 / 10$ bone bridge and bamboo spine.

Patients in our sample underwent hip arthroplasty at late phase, therefore standard $\mathrm{X}$-ray image often show fibrosis in lateral and anterior longitudinal spinal ligament, causing bamboo spine. Interspinous fibrosis cause railway spine. Fibrosis and calcification of tissues cause loss of spinal curvature in lateral X-ray image. Signs of osteoporosis such as increased hyanline and concave scoliosis spine.

Bilateral sacroilitis is a compulsory condition to diagnose AS since it is the soonest and the most common injury in this disease [2]. Bilateral is the most common form. However, in early stages, when X-ray images did not show inflammation, MRI of the iliac provide early diagnosis of sacroiliitis. In our sample, 12/13 hips suffered from late phase sacroiliacs injuries (III - IV).

Hip X-ray images assists surgeons in the diagnosis process to select suitable cup. Injuries in the image were often represented by narrower joint line, sometimes by symmetrical abrasions. At final phase, signs of arthrodesis were visible.

In our study, stage III and IV BASRI-h injuries were the most common, which account for 11/13 hips. These were chronic injuries when hip arthrodesis had present. Osteoporosis was common in patients with hip injuries and AS as well.

$B$ and C Grade Dorr classification accounted for $6 / 13$ cases. This group had bone degradation which directly affect the operation, the initial stability of the stem, the 
generation of bone around the cup that affect the later biological stability, consequently affect the result of the operation.

\section{CONCLUSION}

Based on the study on 10 AS patients with 13 total hip arthroplasties from May 2014 to May 2019 at the 108 Military Central Hospital, we conclude:

\section{Clinical features:}

The mean age at the time of operation was $35.6 \pm 13.7$ years old, all male. Combined form accounted for $9 / 10$ cases. 10/10 patients were operated during the prodromal phase. Limited or complete loss of cervical spine motor function was $7 / 10$ patients, thoracic spine was $8 / 10$ and lumbar spine was 9/10. All 10 patients had bilateral hip injuries. 9/13 hips suffered from moderate to severe pain. Complete loss of hip motor function was common (11/13)

\section{$\mathrm{X}$-ray image}

$10 / 10$ patients suffered from loss of spine curvature, 4/10 railway spine, 5/10 bone bridge and bamboo spine. Sacroiliac injures at stage III and IV were common (12/13), $1 / 13$ at stage II. Stage III and IV BASRI-h injuries were the most common, which account for 11/13 hips, 2/13 at stage II. A, B and $\mathrm{C}$ Grade Dorr classification accounted for 7, 3 and 3 cases, respectively.

\section{REFERENCES}

1. Đoàn Văn Đệ (2010), Bệnh học viêm cột sống dinh khớp, bài giảng chuyên đề Sau đại học, Học viện Quân Y.

2. Trần Ngọc Ân (1980), Viêm cột sống dính khớp tại miền Bắc Việt Nam, luận án Tiển sỹ y học, Bộ môn Nội, trường Đại học Y Hà Nội.

3. Mark R. Brinker, Aaron G. Rosenberg, Laura Kull, Dennis D. Cox (1996), Primary noncemented total hip arthroplasty in patients with ankylosing spondylitis, The Journal of Arthroplasty. 15(1), 52 - 58.

4. Hatim Abid, Mohammed Shimi, Abdelhalim El Ibrahimi, Abdelmajid El Mrini (2014), The total hip arthroplasty in ankylosing spondylitis, Open Journal of Orthropeadics, 4, 117 - 122.

5. Jiss Joseph Panakkal et al (2015), Primary total hip arthroplasty in ankylosing spondylitis - an analysis of 47 hips. Kerala Journal of Orthropeadics, 27(2), 94 - 98.

6. Rajesh Malhotra, Gaurav Sharma (2014), Hip replacement in patients with ankylosing spondylitis, Orthop Muscul Syst, 3, 149.

7. Wanchun Wang, Guoliang Huang, Tianlong Huang and Ren Wu (2014), Bilaterally primary cementless total hip arthroplastyin patients with ankylosing spondylitis. BMC Musculoskeletal Disorder, 15,344 .

8. Jinzhu Zhao, Jia Li, Wei Zheng el al (2014), Low body mass index and blood loss in primary total hip arthroplasty: Results from 236 consecutive ankylosing spondylitis patients. Hindawi Publishing Corporation BioMed Research International, 1 - 6. 